Original Article

\title{
Correlation between the Activities of Daily Living of Stroke Patients in a Community Setting and Their Quality of Life
}

\author{
Kyung Kim, PhD, $\mathrm{PT}^{1)}$, Young Mi KIm, MS, PT ${ }^{1)^{*}}$, Eun Kyung Kim, MS, $\mathrm{PT}^{1)}$ \\ 1) Department of Physical Therapy, College of Rehabilitation Science, Daegu University: 15 Jilyang, \\ Gyeongsan-si, Kyeongbuk 712-714, Republic of Korea
}

\begin{abstract}
Purpose] The present study aimed to determine the correlation between the activities of daily living and the quality of life (QOL) of patients with chronic stroke. [Subjects and Methods] The study subjects were 68 patients with stroke. Three questionnaires were distributed by visiting the subjects. [Results] All the items and total scores of the functional independence measure (FIM) showed a high correlation with the QOL total score. The relationship between the activities of daily living and the total QOL score showed a significant positive correlation. Among the FIM items, mobility and social cognition showed the most significant effects. The modified $\mathrm{r}^{2}$ value was 0.67 , mobility and social cognition explained approximately $67 \%$ of the change in the QOL. [Conclusion] The activities of daily living of the patients with chronic stroke and their QOL showed a high correlation. Among the FIM items, mobility (transfers) and social cognition had the largest effects on the total QOL score.

Key words: Stroke, FIM, QOL
\end{abstract}

(This article was submitted Aug. 13, 2013, and was accepted Oct. 10, 2013)

\section{INTRODUCTION}

Stroke can result in survival with the permanent sequelae impairing in physical, psychological, and social functions. Dependence in activities of daily life living, alteration of emotional and psychological status, and deterioration in social communication can influence the QOL of patients with stroke $^{1}$. Various studies have shown a reduced QOL among patients with stroke compared with healthy individuals. Physical limitations have been stated as a determinant of the QOL.

About $75 \%$ of patients with stroke experience difficulties with daily living activities ${ }^{2}$. If stroke occurs after the age of 65 years, about $80 \%$ of individuals will experience chronic disability $^{3)}$. The number of deaths caused by stroke has decreased due to advancements in medical science. However, as a result, the number of survivors with chronic stroke has increased. In addition to improving survival, the treatment of stroke is important for the patients' quality of life (QOL). As noted by de Hann et al., the ultimate aim of rehabilitation of stroke patients is to improve their $\mathrm{QOL}^{4}$ ).

Most patients with stroke experience role changes due to impaired autonomy caused by difficulty with performing daily living activities, as well as problems with interpersonal relationships. They also face psychosocial maladjust-

*Corresponding author. Young Mi Kim (E-mail: h1015m@ naver.com)

C2014 The Society of Physical Therapy Science. Published by IPEC Inc. This is an open-access article distributed under the terms of the Creative Commons Attribution Non-Commercial No Derivatives (by-ncnd) License $<$ http://creativecommons.org/licenses/by-nc-nd/3.0/>. ment due to long-term stress and strain, which reduces their subjective evaluation ability of their QOL ${ }^{5}$.

Much effort is required to integrate patients with chronic stroke into the local community through the improvement of functional independence and QOL. To help establish rehabilitation objectives for patients with stroke in the future, this study investigated the correlation between the activities of daily living and the QOL of patients with chronic stroke.

\section{SUBJECTS AND METHODS}

This study was conducted from June 20, 2012, to July 19, 2012, and the subjects were 68 persons who attended a program at a health care center or a disabilities welfare center after being diagnosed with stroke. Patients were excluded if they had severe aphasia or cognition problems (MiniMental state Examination [MMSE] score $<20$ ), which can adversely influence the assessment of QOL and daily living activities

Three survey questionnaires were administered to identify the level of participation of the patients in the local community, and the subjects' answers were analyzed. The survey consisted of three categories: general information about the subjects, stroke-specific QOL (SS-QOL) questions, and the functional independence measure (FIM). A physiotherapist from the welfare center, a nurse from the health care center, and two physiotherapists conducted in the surveys using the face-to-face method. All the patients included understood the purpose of this study and provided their written informed consent prior to their participation in the study in accordance with the ethical principles of the Declaration of Helsinki. 
Table 1. Correlation between the FIM and the QOL scores

\begin{tabular}{|c|c|c|c|c|c|c|c|c|}
\hline & FIM_SC & FIM_SP & FIM_MO & FIM_LO & FIM_CO & FIM_SO & FIM_Total & QOL_Total \\
\hline FIM_SC & 1.00 & & & & & & & \\
\hline FIM_SP & $0.66^{* *}$ & 1.00 & & & & & & \\
\hline FIM_MO & $0.99 * *$ & $0.60 * *$ & 1.00 & & & & & \\
\hline FIM_LO & $0.99 * *$ & $0.71 * *$ & $0.99 * *$ & 1.00 & & & & \\
\hline FIM_CO & $0.50 * *$ & $0.88 * *$ & $0.42 * *$ & $0.53^{* *}$ & 1.00 & & & \\
\hline FIM_SO & $0.77^{* *}$ & $0.88^{* *}$ & $0.66^{* *}$ & $0.77 * *$ & $0.83^{* *}$ & 1.00 & & \\
\hline FIM_Total & $0.93 * *$ & $0.81^{* *}$ & $0.99 * *$ & $0.93 * *$ & $0.71^{* *}$ & $0.84 * *$ & 1.00 & \\
\hline QOL_Total & $0.70^{* *}$ & $0.72 * *$ & $0.70 * *$ & $0.72 * *$ & $0.64 * *$ & $0.73 * *$ & $0.80 * *$ & 1.00 \\
\hline
\end{tabular}

$* * \mathrm{p}<0.01$

FIM SC: Self-care in FIM, FIM SP: Sphincter control in FIM, FIM MO: Mobility in FIM, FIM LO: Locomotion in FIM, FIM_CO: Communication in FIM, FIM_SO: Social cognition in FIM

The SS-QOL, which is a disease-specific QOL measure, consists of 49 items encompassing 12 domains (social role, mobility, energy, language, self-care, mood, personality, thinking, upper-extremity function, family role, vision, and work/productivity). Each item is ranked on a 5-point Likert scale. The summary score of this scale is the weighted average of the 12 domains. The total score ranges from 49 to 245, with higher scores indicating better $\mathrm{QOL}^{6}$ ).

To measure the independence level of activities of daily living, the FIM developed by Keith et al. was employed ${ }^{7)}$. The FIM is an 18-item measurement tool, which evaluates the following parameters: self-care, sphincter control, mobility (transfers), locomotion, communication, and social cognition. The items on the FIM are scored on a 7-point ordinal scale ranging from 1 to 7 . The minimum score on the FIM is 18, which indicates a low level of functioning, and the maximum score is 126 , which indicates a very high level of functioning ${ }^{8)}$. The correlation coefficient of the inter-rater reliability ranges between 0.83 and 0.99 , and the test-retest reliability ranges between 0.84 and $0.93^{9}$ ). Data were collected by direct observation of the patient and, when necessary, by interviews with relatives.

Frequency analysis was used to determine the general characteristics of the subjects. Pearson's correlation coefficient was used to assess the correlation among the items of the FIM, the total score, and the SS-QOL total score. Multiple regression analysis using the backward selection method was employed to find the most influential parameter on the QOL total score from among the six items of the FIM. The results were processed using the SPSS 18.0 statistical processing program, And a significance level of $\mathrm{p}=0.01$.

\section{RESULTS}

The subjects consisted of 47 males and 21 females, all of whom had experienced a stroke. Their average age was $64.68 \pm 9.7$ years, and their average period from stroke was $8.46 \pm 5.1$ years.

Table 1 shows the correlations among the six categories of the FIM, the FIM total score, and the QOL total score. All the items and the total score of the FIM showed a high correlation with the QOL total score. The relationship be- tween daily life activities and QOL (total) showed a significant positive correlation $(\mathrm{p}<0.01)$. That is, the more independent the patient's daily living was, the higher the QOL was (total).

Analysis of the importance of the items in the FIM with regard to QOL showed that mobility and social cognition had the most significant effects $(p<0.01)$. The modified $r^{2}$ value was 0.67 , mobility and social cognition explained approximately $67 \%$ of the change in the QOL.

\section{DISCUSSION}

The present study aimed to assess the functional independence level and the QOL of patients with stroke, and to determine the correlation between the FIM items and their QOL. The goal was to provide basic data for treatment planning and the development of interventions for the rehabilitation of patients with chronic stroke in a local community.

Many patients with stroke experience difficulties due to impairment of the central nervous system ${ }^{10)}$. The main purpose of the treatment of stroke is to improve a patient's level of disability to facilitate functional independence, thereby helping to integrate the patient into the local community and improve their QOL ${ }^{11)}$.

The main criterion for assessing the QOL of patients with stroke is their ability to perform daily living activities independently. Various tools have been used to assess the daily living activities in the rehabilitation sector. Among them, the FIM has been utilized in a variety of ways, not only to assess the status of the patient, but also to determine the patient's prognosis and to establish treatment objectives ${ }^{12}$.

In this study, there was a significant correlation among the FIM items and the SS-QOL $(p<0.01)$. All items on the FIM showed a strong correlation with the SS-QOL.

In most previous studies related to the QOL of stroke patients, some of which were cross-sectional and others that included long-term follow-up, the main determinant of QOL was the functional disability level. In a study performed with older Korean stroke patients, physical functioning was the main factor influencing $\mathrm{QOL}^{13)}$. Aprile et al. observed that the QOL assessed by the SF-36 was related to the disability level evaluated by the FIM and the modified Rankin scale in patients with stroke ${ }^{14)}$. Furthermore, 
in a study performed with elderly stroke patients, the most important determinant was their functional status ${ }^{15}$.

In the current study, the results of the regression analysis using the backward selection method showed that mobility and social cognition were the most influential of the FIM items affecting QOL. The mobility item of the FIM refers to transfers to bed, chairs, wheelchair, toilet, and bathtub or shower. If patients lack this ability, they are more dependent on carers, and they have a lower QOL. As noted in previous studies, among older adults, impaired mobility is associated with a loss of independence, reduced QOL, institutionalization, and a higher risk of mortality ${ }^{16}$.

The social cognition item on the FIM refers to social interaction, problem solving, and memory. These items are essential for forming interpersonal relationships, and patients with higher social cognition abilities have better interpersonal relationships. Impairment of these abilities can affect the QOL of patients with stroke. Accordingly, rehabilitation programs should concentrate on increasing the attention, concentration, information processing capabilities, memory, and judgment ability of patients to improve social cognition.

Niemi et al. reported that it is important for self-help programs and rehabilitation institutions to ensure that stroke patients have encouragement, psychological support, adaptation training, and sufficient neuropsychological information ${ }^{17)}$. Such social support would enable patients who are discouraged by stroke to assess themselves more realistically and to live healthier and fuller lives ${ }^{17)}$.

The ability to perform independent activities of daily living is closely related to a quick return to social life. Therefore, functional rehabilitation interventions aimed at chronic stroke patients who have a limited ability of mobility and social cognition should focus on improving their abilities to perform independent activities of daily living, thereby improving their QOL and helping overcome physical, psychological and social problems.

This research focused on only activities of daily living, although there are many other factors that affect the QOL of stroke patients.

\section{REFERENCES}

1) Clarke PJ, Lawrence JM, Black SE: Changes in quality of life over the first year after stroke: findings from the Sunnybrook Stroke Study. Journal of Stroke And Cerebrovascular Diseases: the official journal of National Stroke Association, 2000, 9: 121-127.

2) Sturm JW, Dewey HM, Donnan GA, et al.: Handicap after stroke: how does it relate to disability, perception of recovery, and stroke subtype?: the north North East Melbourne Stroke Incidence Study (NEMESIS). Stroke, 2002, 33: 762-768. [Medline] [CrossRef]

3) Barker WH, Mullooly JP: Stroke in a defined elderly population, 19671985. A less lethal and disabling but no less common disease. Stroke, 1997, 28: 284-290. [Medline] [CrossRef]

4) de Haan R, Aaronson N, Limburg M, et al.: Measuring quality of life in stroke. Stroke, 1993, 24: 320-327. [Medline] [CrossRef]

5) Gulick EE: Correlates of quality of life among persons with multiple sclerosis. Nurs Res, 1997, 46: 305-311. [Medline] [CrossRef]

6) Williams LS, Weinberger M, Harris LE, et al.: Development of a strokespecific quality of life scale. Stroke, 1999, 30: 1362-1369. [Medline] [CrossRef]

7) Keith RA, Granger CV, Hamilton BB, et al.: The functional independence measure: a new tool for rehabilitation. Adv Clin Rehabil, 1987, 1: 6-18. [Medline]

8) Trombly CA, Radomski MV, Trexel C, et al.: Occupational therapy and achievement of self-identified goals by adults with acquired brain injury: phase II. The American Journal of Occupational Therapy, 2002, 56: 489498.

9) Dickson HG, Kohler F: Interrater reliability of the 7-level functional independence measure (FIM). Scand J Rehabil Med, 1995, 27: 253-256. [Medline]

10) Howard G, Howard VJ, Katholi C, et al.: Decline in US stroke mortality: an analysis of temporal patterns by sex, race, and geographic region. Stroke, 2001, 32: 2213-2220. [Medline] [CrossRef]

11) Won JI: Necessity of community-based rehabilitation system after stroke. The Korea Contents Association, 2007, 8: 16-26.

12) Park SY, Won JI, Lee MY: Rash analysis of FIM physical items in patients with stroke in Korea. J Korean Acad Univ Trained Phys Therapists, 2010, 17.

13) Gunaydin R, Karatepe AG, Kaya T, et al.: Determinants of quality of life $(\mathrm{QoL})$ in elderly stroke patients: a short-term follow-up study. Arch Gerontol Geriatr, 2011, 53: 19-23. [Medline] [CrossRef]

14) Aprile I, Piazzini DB, Bertolini C, et al.: Predictive variables on disability and quality of life in stroke outpatients undergoing rehabilitation. Neurological sciences: official journal of the Italian Neurological Society and of the Italian Society of Clinical Neurophysiology, 2006, 27: 40-46.

15) Mackenzie AE, Chang AM: Predictors of quality of life following stroke. Disabil Rehabil, 2002, 24: 259-265. [Medline] [CrossRef]

16) von Bonsdorff $M$, Rantanen $T$, Laukkanen $P$, et al.: Mobility limitations and cognitive deficits as predictors of institutionalization among community-dwelling older people. Gerontology, 2006, 52: 359-365. [Medline] [CrossRef]

17) Niemi ML, Laaksonen R, Kotila M, et al.: Quality of life 4 years after stroke. Stroke, 1988, 19: 1101-1107. [Medline] [CrossRef] 